\title{
Estimating leaf functional traits by inversion of PROSPECT: Assessing leaf dry matter content and specific leaf area in mixed mountainous forest
}

\author{
Abebe Mohammed Ali ${ }^{\mathrm{a}, \mathrm{b}, *}$, Roshanak Darvishzadeh ${ }^{\mathrm{a}}$, Andrew K. Skidmore ${ }^{\mathrm{a}}$, \\ Iris van Duren ${ }^{a}$, Uta Heiden ${ }^{c}$, Marco Heurich ${ }^{\mathrm{d}}$ \\ ${ }^{a}$ Faculty of Geo-Information Science and Earth Observation (ITC), University of Twente, P.O. Box 217, 7500 AE Enschede, The Netherlands \\ ${ }^{\mathrm{b}}$ Department of Geography and Environmental Studies, Wollo University, P.O. Box 1145, Dessie, Ethiopia \\ ${ }^{c}$ German Aerospace Center (DLR), German Remote Sensing Data Center (DFD) Oberpfaffenhofen, 82234 Wessling, Germany \\ d Bavarian Forest National Park, 94481, Grafenau, Germany
}

\section{A R T I C L E I N F O}

\section{Article history:}

Received 30 April 2015

Received in revised form 16 October 2015

Accepted 3 November 2015

Available online 16 November 2015

\section{Keywords:}

Functional leaf traits

Radiative transfer model

PROSPECT

LDMC

SLA

\begin{abstract}
A B S T R A C T
Assessments of ecosystem functioning rely heavily on quantification of vegetation properties. The search is on for methods that produce reliable and accurate baseline information on plant functional traits. In this study, the inversion of the PROSPECT radiative transfer model was used to estimate two functional leaf traits: leaf dry matter content (LDMC) and specific leaf area (SLA). Inversion of PROSPECT uSually aims at quantifying its direct input parameters. This is the first time the technique has been used to indirectly model LDMC and SLA. Biophysical parameters of 137 leaf samples were measured in July 2013 in the Bavarian Forest National Park, Germany. Spectra of the leaf samples were measured using an ASD FieldSpec3 equipped with an integrating sphere. PROSPECT was inverted using a look-up table (LUT) approach. The LUTs were generated with and without using prior information. The effect of incorporating prior information on the retrieval accuracy was studied before and after stratifying the samples into broadleaf and conifer categories. The estimated values were evaluated using $R^{2}$ and normalized root mean square error (nRMSE).

Among the retrieved variables the lowest nRMSE (0.0899) was observed for LDMC. For both traits higher $R^{2}$ values ( 0.83 for LDMC and 0.89 for SLA) were discovered in the pooled samples. The use of prior information improved accuracy of the retrieved traits. The strong correlation between the estimated traits and the NIR/SWIR region of the electromagnetic spectrum suggests that these leaf traits could be assessed at canopy level by using remotely sensed data.
\end{abstract}

(c) 2015 Elsevier B.V. All rights reserved.

\section{Introduction}

Components of biodiversity that influence ecosystem dynamics, stability, productivity, nutrient balance and other aspects of ecosystem functioning are collectively referred as functional diversity (e.g., Tilman et al., 1997; Tilman, 2001). Most ecologists now agree that a major determinant of ecosystem functioning is functional diversity, rather than number of species per se (Díaz and Cabido, 2001). By quantifying functional diversity in natural communities, researchers gain additional understanding of the spatial and temporal distribution of biodiversity, ecosystem services and

* Corresponding author at: Faculty of Geo-Information Science and Earth Observation (ITC), University of Twente, P.O. Box 217, Enschede, 7500 AE, The Netherlands.

E-mail address: abebemohammed@yahoo.co.uk (A.M. Ali). plant community productivity (Cadotte et al., 2009; Lavorel et al., 2011). It is believed that better conservation and restoration decisions can be made by measuring and understanding functional diversity (Cadotte et al., 2011). This realization has underpinned the shift in focus of biodiversity research from species diversity to functional diversity (Tilman, 2001).

Like species diversity, functional diversity is quantified on the basis of trait values of organisms (Petchey and Gaston, 2006; Zhang et al., 2012). A trait is any measurable morphological, physiological or phenological feature of an organism (Violle et al., 2007). In plants, a trait is called a functional trait (e.g., specific leaf area) when it affects plant fitness indirectly via its impacts on plant growth, reproduction, and survival (Violle et al., 2007). It is the combination of plant functional traits that determines how plants respond to environmental factors, affect other trophic levels, and influence 
ecosystem processes and services (Zhang et al., 2012). For instance, plants growing in a resource-rich environment will have a relatively high specific leaf area and low dry matter content, whereas for plants growing in a resource-poor environment the opposite is true (Wilson et al., 1999). Traits also provide a link between ecosystem functional diversity and species richness (Carlson et al., 2007; Gregory, 2008). The functional traits are increasingly used to investigate community structure and ecosystem functioning, as well as to classify species into functional types (Smith et al., 1997) or for to validate global vegetation models (Albert et al., 2010).

In general, plant traits can be categorized into four groups (Cornelissen et al., 2003): whole-plant traits (e.g., growth form and height), stem and belowground traits (e.g., stem specific density and specific root length), regenerative traits (e.g., seed mass and dispersal mode) and leaf functional traits. Two fundamental leaf functional traits that are of central interest for researchers are Leaf Dry Matter Content (LDMC) and Specific Leaf Area (SLA) (Wilson et al., 1999; Asner et al., 2011). The LDMC, sometimes referred to as tissue density, is the dry mass of a leaf divided by its fresh mass, commonly expressed in $\mathrm{mg} / \mathrm{g}$ (Cornelissen et al., 2003). It reflects plant growth rate and carbon assimilation and is a better predictor of location on an axis of resource capture, usage and availability (Wilson et al., 1999). The SLA is defined as the leaf area per unit of dry leaf mass usually expressed in $\mathrm{m}^{2} / \mathrm{kg}$ (Cornelissen et al., 2003). It is referred to as leaf mass per unit area, as specific leaf mass, as well as leaf specific mass. SLA links plant carbon and water cycles, and provides information on the spatial variation of photosynthetic capacity and leaf nitrogen content (Pierce et al., 1994). According to the latter, "SLA is indicative of plant physiological processes such as light capture, growth rates and life strategies of plants". A worldwide foliar dataset indicates that $82 \%$ of all variation in photosynthetic capacity can be explained by SLA and nitrogen (Wright et al., 2004). SLA is species-specific, but significant plasticity exists within and between individual plants of the same species (Pierce et al., 1994; Asner et al., 2011).

Besides their independent role as important ecological indicators, LDMC and SLA could be used to estimate leaf thickness (LT). The estimation of LT from the two traits has been investigated in detail by Vile et al. (2005). This implies SLA is a compound trait which is inversely proportional to the product of LDMC and LT. A study by Hodgson et al. (2011) found that LDMC $\times$ LT accounted for nearly three quarters of the observed variation in SLA and that very different combinations of LT and LDMC regularly generate similar values of SLA. However, there are misconceptions in the definition of the stated traits. In many publications, leaf mass per area (LMA or $C_{\mathrm{m}}$ ), which is the inverse of SLA, is defined as LDMC.

Several trait data bases have been established worldwide through field measurements (e.g., Kleyer et al., 2008; Kattge et al., 2011). However, acquiring information on such traits purely on the basis of field measurements is labor-intensive and timeconsuming, and thus expensive. Remotely sensed data can play a critical role in acquiring such data at broad spatial scales. Hyperspectral remote sensing has the advantage of providing detailed and continuous spectral information, which can potentially be used for measuring these traits. Previous studies have focused on using hyperspectral data to quantify biochemical and biophysical variables of vegetation, such as chlorophyll content, nitrogen and leaf area index (Darvishzadeh et al., 2008a; Vohland and Jarmer, 2008; Asner and Martin, 2009; Knox et al., 2010; Skidmore et al., 2010; Asner et al., 2011; Laurent et al., 2011; Ramoelo et al., 2011; Asner and Martin, 2012; Ramoelo et al., 2012). Hyperspectral remote sensing has also been used to map canopy functional and species diversity (Carlson et al., 2007; Papeş et al., 2010) and to estimate biodiversity (even simply as the number of species) (Lauver, 1997; Gould, 2000; Saatchi et al., 2008; Papeş et al., 2010; Féret and Asner, 2011; Ruiliang, 2011; Féret and Asner, 2014). However, directly mapping individual species from remote sensing becomes difficult at larger scales and in ecosystems with very high species variability. An alternative approach to mapping species is to estimate plant functional traits, particularly those found in tree crown leaves, and to use these for assessing and monitoring biodiversity (Carlson et al., 2007; Gregory, 2008).

The methods applied to retrieve plant traits from remote sensing data can be grouped into statistical and physical (Darvishzadeh et al., 2008b; le Maire et al., 2008): statistical techniques are used to find a relation between the plant trait measured in situ and its spectral reflectance or some transformation of reflectance. Vegetation indices are widely used in this approach. When hyperspectral data are utilized, it is possible to select the most informative narrow spectrum features from the entire electromagnetic spectrum domain and use them for simple and fast assessment of vegetation properties (Broge and Mortensen, 2002). However, statistical methods are known to be site-specific and lack generalization. An alternative is to use a deductive or physical model approach (Radiative Transfer Model (RTM)) inversion, which is based on physical laws.. Running an RTM enables the creation of a simulated training database covering a wide range of situations and configurations. Such forward RTM simulations allow for sensitivity studies of parameters and development of vegetation indices. This makes RTM inversion approaches more powerful than statistical methods. However, the retrieval of variables through RTMs inversion is ill-posed, since different combination of the input parameters may produce the same spectral signature. To overcome the effect of the ill-posed problem, Combal et al. (2003) recommended the use of prior information. Several studies have reported significant improvement to the accuracy of parameter retrieval after using prior information (e.g., Malenovsky et al., 2006; Dasgupta et al., 2009); others (Feret et al., 2011; Romero et al., 2012) have tried to exclude unrealistic combinations of input parameters by applying a linear regression equation derived from correlating the input parameters.

Leaf RTMs simulate leaf reflectance and transmittance by using certain input parameters derived from leaves. There are a number of leaf RTMs and each one requires a different number of input parameters. One such leaf radiative transfer model is the LIBERTY (Leaf Incorporating Biochemistry Exhibiting Reflectance and Transmittance Yields) model (Dawson et al., 1998) for conifer needles. However, it requires many input parameters which need to be obtained by intensive fieldwork and laboratory analysis (Malenovsky et al., 2006; Morsdorf et al., 2009). Another widely applied leaf radiative transfer model is PROSPECT (Jacquemoud and Baret, 1990). PROSPECT, which stands for PROpriétés SPECTrales (French for Spectral Properties). It simulates leaf reflectance and transmittance and is the most popular leaf optical properties model of all those published since 1990 (Jacquemoud et al., 2009).

Although much work has been done on estimating plant traits from remote sensing, the estimation of LDMC and SLA at all scales (i.e., leaf, canopy and landscape) is rare. To our knowledge, the use of remote sensing techniques to estimate LDMC has not yet been tested at any scale. Compared to other biophysical variables, studies conducted on SLA are also limited and have mainly been conducted using statistical methods at a canopy scale. Lymburner et al. (2000) tested several existing vegetation indices in order to estimate SLA from Landsat TM imagery and found a strong correlation between average canopy SLA and green, red, NIR and MIR reflectance of Landsat TM data. A strong correlation between leaf mass per area and reflectance in the $750-2500 \mathrm{~nm}$ wavelength range has been also reported for tropical rainforest leaf samples (Asner and Martin, 2008; Asner et al., 2011). Normalized indices for leaf mass per area at leaf and canopy scales have been developed only recently, by le Maire et al. (2008) and Feret et al. (2011). However, these indices need to be tested on other images, sites and canopies (le Maire 
Table 1

Distribution of collected samples, by species.

\begin{tabular}{|c|c|c|}
\hline Category & Species & No. of samples \\
\hline \multirow[t]{5}{*}{ Broadleaf trees } & 1. European beech & 44 \\
\hline & 2. Sycamore maple & 4 \\
\hline & 3. Mountain ash & 3 \\
\hline & 4. Goat willow & 2 \\
\hline & Subtotal & 53 \\
\hline \multirow[t]{3}{*}{${ }^{\mathrm{a}}$ Conifers } & 1. Norway spruce & 63 \\
\hline & 2. Fir & 21 \\
\hline & Subtotal & 84 \\
\hline Total No. of samples & & 137 \\
\hline
\end{tabular}

a Equal number of samples were taken from the current growing period (C), second growing period $(\mathrm{C}+)$ and three and more growing periods $(\mathrm{C}++)$ needle age class (i.e., the numbers of samples per age class were 21 for Norway spruce and 7 for fir species).

et al., 2008). Physical models, which are supposed to be much more robust than statistical approaches, have not been tested for LDMC and SLA estimations. Our study therefore aimed to investigate how accurately and precisely the LDMC and SLA can be estimated in heterogeneous forests at leaf level by using radiative transfer models, so that the application can be extended to canopy and landscape scales.

\section{Data and methods}

\subsection{Study area and field data collection}

The area chosen for this study was the mixed mountain forest of the Bavarian Forest National Park, which is more heterogeneous in tree species than similar areas in the region. It is located in southeastern Germany along the border with the Czech Republic (490 $3^{\prime} 19^{\prime \prime} \mathrm{N}, 13012^{\prime} 9^{\prime \prime} \mathrm{E}$ ). Elevation varies from $600 \mathrm{~m}$ to $1473 \mathrm{~m}$ above sea level. The climate of the region is temperate, with high annual precipitation ( $1200 \mathrm{~mm}$ to $1800 \mathrm{~mm}$ ) and low average annual temperature ( $3^{\circ}$ to $6^{\circ}$ Celsius). Heavy snow cover is characteristic of the area in winter. Brown soils are the predominant soil type at lower altitude (below $900 \mathrm{~m}$ a.s.l) whereas at high altitude (above $900 \mathrm{~m}$ a.s.l) brown soils and brown podzolic soil predominate. The soils in the area are naturally acidic and low in nutrient content (Heurich et al., 2010).

The natural forest ecosystems of the Bavarian Forest National Park vary with altitude: there are alluvial spruce forests in the valleys, mixed mountain forests on the hillsides and mountain spruce forests in the high areas. The dominant tree species include European beech (Fagus sylvatica), Norway spruce (Picea abies) and Fir (Abies alba). In the mixed mountain forests Sycamore maple (Acer pseudoplatanus L.), Mountain ash (Sorbus aucuparia L.) and Goat willow (Salix caprea) are also found (Heurich and Neufanger, 2005).

A field campaign was conducted between 11 July and 23 August 2013. The study area was stratified into broadleaf, conifers and mixed forest categories. Considering the nature of the forest heterogeneity, time and cost constraints, 26 plots ( 8 in broadleaf, 7 in conifer and 12 in mixed stands) were randomly selected within each forest category. Each plot was 30 by $30 \mathrm{~m}$, so that the samples could subsequently be used to estimate variables from medium resolution remote sensing data. Leaf samples were then collected from each tree species found in the plot (Table 1). As the two traits of interest (SLA and LDMC) tend to vary as one moves downward from the top of the tree, all the samples were taken from mature sunlit leaves at the top of the canopy. A crossbow was used to shoot an arrow attached to a fishing line at a branch with sunlit leaves. Once the fishing line had passed around the targeted branch, the fishing line was used to feed a rope over the branch and then the branch was pulled down gently until it broke off. Leaves/shoots were immediately removed from the branch and SPAD chlorophyll measurements were made for the broadleaf samples. The shoots of the conifer needles were classified into three needle age classes: current growing period $(C)$, second growing period $(C+)$ and three and more growing periods $(\mathrm{C}++)$. The samples were then placed in a zip-locked plastic bag together with wet pulp paper and transported to the laboratory in a portable cooler with frozen icepacks. In the laboratory, the leaf samples were stored in a cold dark room and processed within the day of collection.

\subsection{Laboratory measurements}

\subsubsection{Physical variable measurements}

The biophysical characteristics of the samples such as fresh and dry weight and hemispherical surface area were acquired simultaneously with the spectra measurements. The fresh weight of each sample was determined (before the spectral measurements) by using a digital scale of high precision. Leaf area of broadleaf samples was measured using the LI-3000C portable leaf area meter ( $\mathrm{Li}-\mathrm{Cor}$, Inc, Lincoln, NE, USA). In the case of the conifer needles, the surface of the sample needles was scanned using an HP double lamp desktop scanner at a resolution of $1200 \mathrm{dpi}$; the needle projections were computed from the greyscale images using ImageJ image processing software (which is freely available online). Norway spruce needles are cylindrical and therefore their total surface was first computed as a projected area multiplied by a universal conversion factor of 2.57 derived experimentally for Norway spruce needles (Waring, 1983). Then, the total needle surface area was divided by two to acquire the hemispherical-surface projection of sampled spruce needles. Finally, the samples were oven-dried at $80^{\circ} \mathrm{C}$ for $48 \mathrm{~h}$ and their dry biomass was weighed. The leaf traits were then computed using the sample leaves or needles area, fresh weight and dry weight. The summary statistics of all the measured variables are presented in Table 2.

\subsubsection{Spectral measurements}

Hemispherical reflectance and transmittance from 350 to $2500 \mathrm{~nm}$ with $1 \mathrm{~nm}$ spectral resolution were measured using a FieldSpec ${ }^{\circledR} 3$ portable spectroradiometer equipped with an integrating sphere manufactured by Analytical Spectral Devices, Inc (ASD), USA. The spectral measurement for each sample was obtained by averaging the spectra on 10 randomly selected leaves in the case of broadleaf species and on 12-16 needles for conifers. Care was taken to avoid large primary and secondary veins during the spectral measurement. In order to minimize the effect of signal variance, two hundred scans were averaged in every spectra measurement to a single spectrum. A calibrated reference standard (with approximately 99\% reflectance) was used to convert raw radiance to reflectance.

Whereas the spectral measurement of broadleaf material is straightforward, the spectral measurement of conifer needles is not. This is because the conifer needles are very small and do not cover the sample port of the integrating sphere, which has a port diameter of $15 \mathrm{~mm}$ for reflectance and $13.5 \mathrm{~mm}$ for transmittance. Therefore, the technique first developed by Daughtry et al. (1989) and later revised by (Mesarch et al., 1999) was applied to measure the spectral property of the conifer needles. A universal sample holder that could accommodate all lengths of conifer needles was designed, following Malenovsky et al. (2006). Needles were detached from each sample shoot, placed on the sample holder, secured with scotch tape and leaving a space of approximately one needle's width between needles to avoid multiple reflectance from adjacent needles (Daughtry et al., 1989). The sample holder was carefully placed at the sample port of the integrating sphere, and reflectance and transmittance spectra were acquired 
Table 2

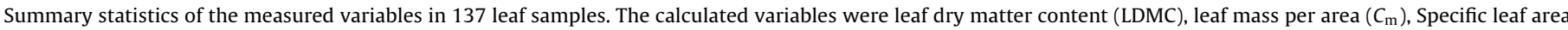
(SLA) and leaf water content $\left(C_{\mathrm{w}}\right)$.

\begin{tabular}{|c|c|c|c|c|c|}
\hline Category & Basic statistics & $C_{\mathrm{m}}\left(\mathrm{g} / \mathrm{cm}^{2}\right)$ & $C_{\mathrm{w}}\left(\mathrm{g} / \mathrm{cm}^{2}\right)$ & LDMC (mg/g) & $\operatorname{SLA}\left(\mathrm{cm}^{2} / \mathrm{g}\right)$ \\
\hline \multirow[t]{4}{*}{ Broadleaf } & Minimum value & 0.0034 & 0.0063 & 337.3 & 73.48 \\
\hline & Maximum value & 0.0136 & 0.0156 & 541.3 & 294.09 \\
\hline & Mean value & 0.0079 & 0.0092 & 460.6 & 135.38 \\
\hline & St. deviation & 0.0021 & 0.0021 & 42.70 & 38.25 \\
\hline \multirow[t]{4}{*}{ Conifers } & Minimum value & 0.0110 & 0.0116 & 361.5 & 34.36 \\
\hline & Maximum value & 0.0291 & 0.0337 & 598.4 & 90.74 \\
\hline & Mean value & 0.0202 & 0.0247 & 449.7 & 51.52 \\
\hline & St. deviation & 0.0039 & 0.0043 & 43.20 & 10.92 \\
\hline
\end{tabular}

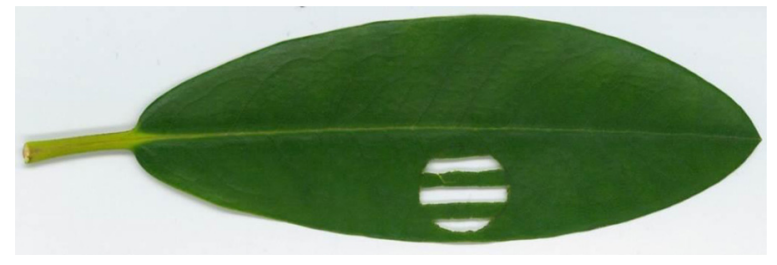

Fig. 1. The holes cut into a broadleaf sample to mimic conifer needle samples set up on the integrating sphere sample port.

following the port configuration procedures of the ASD integrating sphere.

A black painted paper mask with a $15 \mathrm{~mm}$ diameter circular aperture was precisely superimposed on the samples and photographs were taken using a 16.1 mega pixel Panasonic DCM-TZ35 camera. Then the gap fraction (GF) between illuminated needles was calculated based on the illuminated area of the sample port, which was $9 \mathrm{~mm}$ diameter for both reflectance and transmittance. The illuminated areas of the samples were clipped by drawing a circle of $9 \mathrm{~mm}$ diameter at the center of each picture. The proportion of pixels with gaps between needles was then determined by dividing the number of pixels with gaps into the total number of pixels found in the $9 \mathrm{~mm}$ circular aperture area using Image J software. Then, the following equations (Eqs. (1) and (2)) were adapted from Mesarch et al. (1999) for the Field spec ASD spectrometer, to compute the hemispherical reflectance and transmittance of the sampled needles.

Reflectance $=\frac{\frac{\rho-\mathrm{Rd}}{1-\mathrm{Rd}} \times \mathrm{Rr}}{1-\mathrm{GF}}$

Transmittance $=\left(\frac{\tau-\mathrm{Rd}}{1-\mathrm{Rd}}\right)-(\mathrm{PwGF}) \frac{1}{1-\mathrm{GF}} \mathrm{Rr}$

where $\rho$ and $\tau$ are measured sample reflectance and transmittance, $\mathrm{Rd}$ is stray light (measured in reflectance mode), $\mathrm{Rr}$ is reference of sample reflectance, GF is the gap fraction of the sample, and Pw is the reflectance of the integrating sphere wall. Stray light (ambient light) inside the integrating sphere was measured as a radiation flux of the empty illuminated sample port in reflectance mode. The reflectance of the integrating sphere wall was determined by: $\mathrm{PW}=\frac{\mathrm{Ftn}}{1-\mathrm{Fn}}$ Rrhere Ftn and Fn are radiance measurements in transmittance and reflectance modes with no sample (Daughtry et al., 1989).

To check the reliability of the method, we conducted some preliminary experiments before measuring the conifer needles. The test entailed using a broadleaf sample that covered the entire port of the integrating sphere. First we measured the reflectance and transmittance while the entire port of the integrating sphere was covered by the selected leaf sample. In the exact circular area of the leaf that covered the port we then cut holes (Fig. 1) to mimic the arrangement of the conifer needles on the sample port; we henceforth refer to the sample treated this way as the striped sample. We repositioned the cut circular area of the striped sample over the port and repeated the spectral measurements. We then adjusted the striped sample's reflectance and transmittance so that we could evaluate the gap fraction effects on the measured spectra of conifer needles. This reliability test yielded RMSE $=0.08$ for transmittance and RMSE $=0.023$ for reflectance. Larger errors, particularly for transmittance, were observed in the wavelength ranges 750-1300 $\mathrm{nm}$ and 1900-2500 nm (Fig. 2).

Through visual inspection, spectral measurements in the ranges of 350-400 and 2351-2500 were found to be noisy and were removed from all spectral datasets. The Savitzky-Golay smoothing filter (Savitzky and Golay, 1964) with a second order polynomial function and bandwidth of $15 \mathrm{~nm}$ was applied, to eliminate random noise within the reflectance and transmittance spectral signatures.

\subsection{PROSPECT model simulation}

Testing the accuracy and robustness of physical (i.e., deductive) models, demand a large volume of data. Obtaining this data by measuring real leaves would be very laborious. A solution is to use radiative transfer models (RTM) to generate a large spectral dataset incorporating a wide range of parameters and variability. Leaf RTMs simulate leaf reflectance and transmittance properties by using specific input parameters derived from leaves. The most popular RTM for leaf parameters is the PROSPECT leaf optical properties model (Jacquemoud et al., 2009). It idealizes a leaf as a stack of plates composed of absorbing and diffusing constituents. It simulates leaf optical properties (i.e., reflectance and transmittance) parameterized by the following inputs: chlorophyll content $\left(C_{\mathrm{ab}}\right)$ in $\mu \mathrm{g} / \mathrm{cm}^{2}$, leaf dry mass per unit area $\left(C_{\mathrm{m}}\right)$ in $\mathrm{mg} / \mathrm{cm}^{2}$, leaf water mass per unit area $\left(C_{\mathrm{w}}\right)$ in $\mathrm{mg} / \mathrm{cm}^{2}$, and effective number of leaf layers $(N)$ (Jacquemoud and Baret, 1990). The model has been widely applied to broadleaf vegetation to estimate chlorophyll content (Zhang et al., 2008; Ma et al., 2012; Rivera et al., 2013). It has also been successfully recalibrated and used to simulate the optical properties of coniferous needles (Malenovský et al., 2008; Morsdorf et al., 2009). The model was revised by Feret et al. (2008) to improve its performance and applicability.

Both PROSPECT-4 and PROSPECT-5 were released at the same time. The difference between them is that in PROSPECT-5 leaf pigments are separated into total chlorophylls and total carotenoids, which improves the chlorophyll retrieval (Feret et al., 2008). Since we were not interested in pigment retrieval, in this study, PROSPECT- 4 was used to simulate leaf reflectance and transmittance. SLA $\left(\mathrm{cm}^{2} / \mathrm{mg}\right)$ was computed as $1 / C_{\mathrm{m}}$. Since LDMC is the amount of leaf dry weight per unit of fresh leaf mass, this parameter was derived from $C_{\mathrm{m}}$ and $C_{\mathrm{w}}$. Eqs. (3)-(6) show the derivation of LDMC from $C_{\mathrm{m}}$ and $C_{\mathrm{w}}$ :

$\mathrm{LDMC}=\frac{W_{\mathrm{d}}}{W_{\mathrm{f}}}$

$C_{\mathrm{w}}=\frac{W_{\mathrm{f}}-W_{\mathrm{d}}}{A}$ 

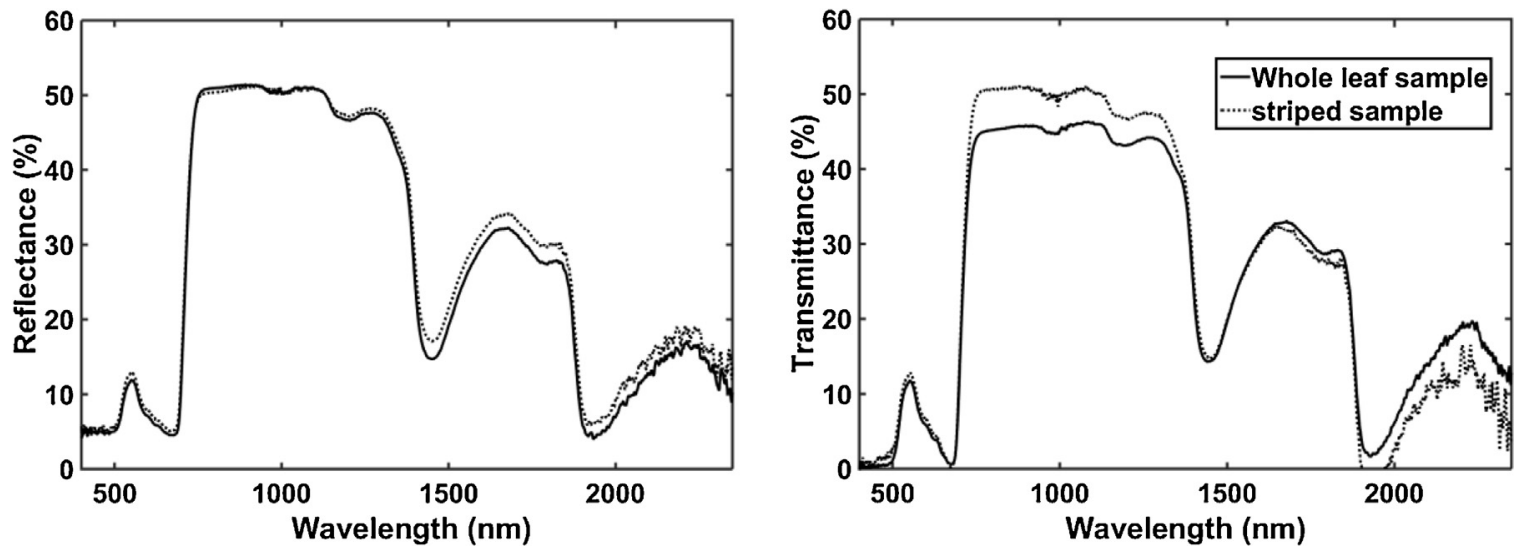

Fig. 2. Comparison of reflectance (left) and Transmittance (right) spectra of a whole leaf sample and striped leaf sample taken from a broadleaf tree.
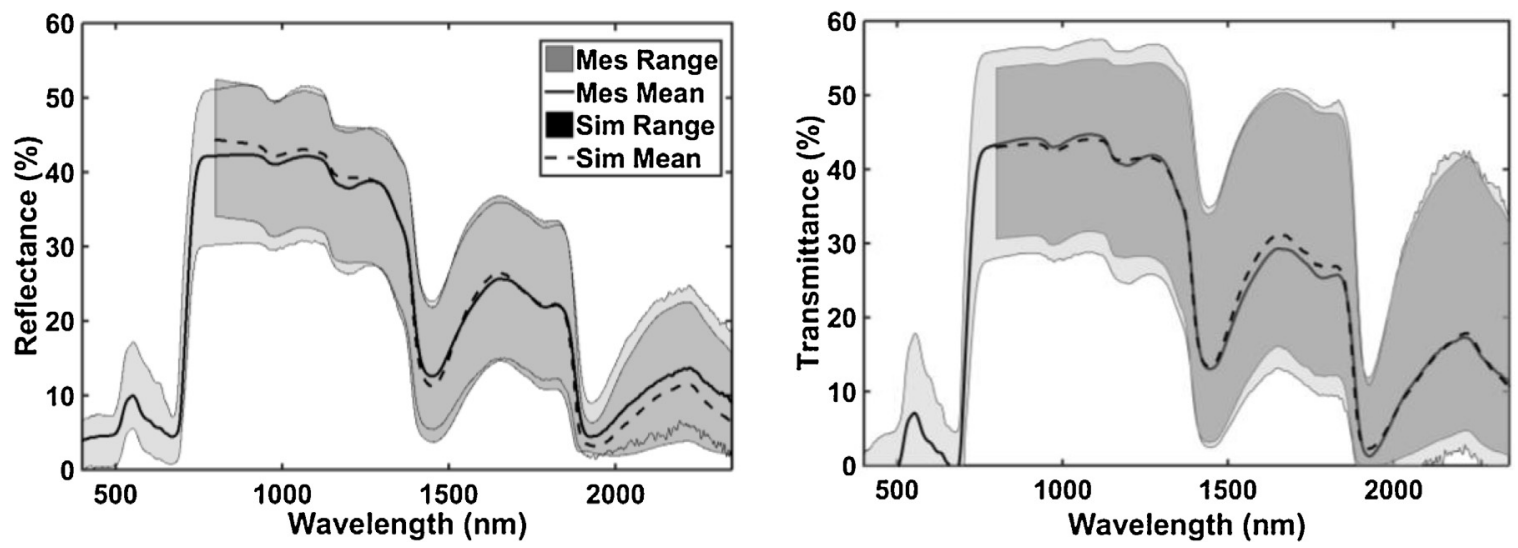

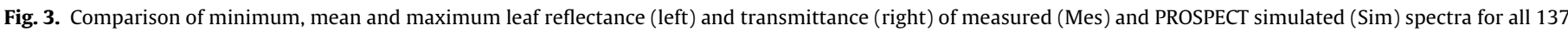
samples collected in the mixed mountain forests of the Bavarian Forest National Park.

$C_{\mathrm{m}}=\frac{W_{\mathrm{d}}}{A}$

By reformulating Eqs. (4) and (5) for $W_{\mathrm{d}}$ and $W_{\mathrm{f}}$

$\mathrm{LDMC}=\frac{C_{\mathrm{m}}}{C_{\mathrm{m}}+C_{\mathrm{w}}}$

where LDMC is leaf dry matter content in $\mathrm{mg} / \mathrm{g}, C_{\mathrm{w}}$ is leaf water mass per area in $\mathrm{mg} / \mathrm{cm}^{2}, C_{\mathrm{m}}$ is leaf dry mass per area in $\mathrm{cm}^{2} / \mathrm{mg}$, $W_{\mathrm{d}}$ and $W_{\mathrm{f}}$ are leaf dry and fresh weights in $\mathrm{mg}$ and $\mathrm{g}$ respectively and $A$ is leaf area in $\mathrm{cm}^{2}$.

Many studies have confirmed that wavelengths in the visible and near infrared region (400-800 nm) are highly sensitive to leaf pigments such as chlorophylls and carotenoids, while the shortwave infrared region is the most sensitive region for retrieving parameters related to dry matter (Jacquemoud et al., 1996; Asner et al., 2009, 2011; Romero et al., 2012). Therefore, the spectral region from 800 to $2350 \mathrm{~nm}$ was used to retrieve LDMC and SLA. This range avoids the need to measure leaf pigments for model calibration and validation, since they have no impact on the selected range spectral signature (Romero et al., 2012). The latter was also confirmed by sensitivity analysis for the chlorophyll, by running the model in forward mode.

\subsubsection{Generation of look-up tables}

Various inversion algorithms can be used to retrieve a given parameter through RTMs. One of the most popular and efficient is the Look-Up Table (LUT) approach (Dasgupta et al., 2009). It involves performing repeated simulations of spectra by using the model with all combinations of the input parameters constrained by reasonable ranges of the input variables. The LUT is then inverted during retrievals.

We followed the general procedures set by Feret et al. (2008) in the LUT generation and inversion. The first step was to determine the structural input parameter $N$ of the 137 leaf samples, which could neither be collected in the field nor measured in the laboratory. The wavelength-independent parameter $N$ was retrieved for each sample by inverting the model by using simulation at three wavelengths corresponding to maximum reflectance, maximum transmittance and minimum absorption of the measured spectra (Jacquemoud and Baret, 1990; Feret et al., 2008). Although leaf structure parameter $N$ corresponds to the number of leaf layers and is most plausible as a whole number, to take account of the subtle variations in leaf structure, $N$ can be considered as a real number with continuous values (Jacquemoud et al., 1996). To start the simulation the maximum and minimum values found in the literature were used for the range of $N$. Therefore, $N$ was set between 0.5 and 3.0 (Combal et al., 2003; Malenovsky et al., 2006; Féret and Asner, 2011). A mini LUT $(251 N \times 137=34387)$ was generated from all possible combinations of the field measured values of $C_{\mathrm{m}}$ and $C_{\mathrm{W}}$ (137 pairs) with that of $N$ values set at a step of 0.01 within the stated range ( $251 \mathrm{~N}$ values). The structural parameter $N$ was then retrieved (here after considered as measured value of $N$ ) using the simulated spectra which best fit the measured spectra of each sample. The search for best simulation was determined by calculating 
Table 3

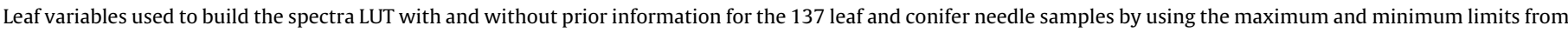
the literature and field observation.

\begin{tabular}{|c|c|c|c|c|c|c|}
\hline \multirow[t]{2}{*}{ Method } & \multirow[t]{2}{*}{ Category } & \multicolumn{5}{|c|}{ Input variables } \\
\hline & & & $C_{\mathrm{ab}}\left(\mu \mathrm{g} / \mathrm{cm}^{2}\right)$ & $C_{\mathrm{m}}\left(\mathrm{g} / \mathrm{cm}^{2}\right)$ & $C_{\mathrm{w}}\left(\mathrm{g} / \mathrm{cm}^{2}\right)$ & $N$ \\
\hline \multirow{3}{*}{$\begin{array}{l}\text { Unconstrained } \\
\text { approach (without } \\
\text { prior information) }\end{array}$} & \multirow{3}{*}{$\begin{array}{l}\text { All the three strata } \\
\text { (broadleaf, conifer and } \\
\text { pooled samples }\end{array}$} & Min & 40 & 0.0030 & 0.0060 & 0.50 \\
\hline & & Max & 40 & 0.0295 & 0.0340 & 3.00 \\
\hline & & Step & - & 0.0005 & 0.0005 & 0.05 \\
\hline \multirow{9}{*}{$\begin{array}{l}\text { Constrained approach } \\
\text { (with prior } \\
\text { information) }\end{array}$} & \multirow[t]{3}{*}{ Broadleaf samples } & Min & 40 & 0.0034 & 0.0063 & 1.0 \\
\hline & & Max & 40 & 0.0136 & 0.0156 & 1.85 \\
\hline & & Step & - & 0.0005 & 0.0005 & 0.05 \\
\hline & \multirow[t]{3}{*}{ Conifer needles } & Min & 40 & 0.0110 & 0.0116 & 1.0 \\
\hline & & Max & 40 & 0.0291 & 0.0337 & 2.25 \\
\hline & & Step & - & 0.0005 & 0.0005 & 0.05 \\
\hline & \multirow[t]{3}{*}{ Pooled samples } & Min & 40 & 0.0034 & 0.0063 & 1.0 \\
\hline & & Max & 40 & 0.0291 & 0.0337 & 2.25 \\
\hline & & Step & - & 0.0005 & 0.0005 & 0.05 \\
\hline
\end{tabular}

Table 4

Descriptive statistics of the structural parameter $N$ values for sampled trees as retrieved by inversion of the PROSPECT- 4 model at three selected wavelengths in the infrared region.

\begin{tabular}{|c|c|c|c|c|c|c|c|c|c|}
\hline & \multirow[t]{2}{*}{ Beech } & \multirow[t]{2}{*}{ Maple } & \multirow[t]{2}{*}{ Mountain ash } & \multicolumn{3}{|l|}{ Fir } & \multicolumn{3}{|c|}{ Norway spruce } \\
\hline & & & & $\mathrm{C}$ & $\mathrm{C}+$ & $\mathrm{C}++$ & $\mathrm{C}$ & $\mathrm{C}+$ & $\mathrm{C}++$ \\
\hline Mean & 1.42 & 1.43 & 1.70 & 1.63 & 1.69 & 1.89 & 1.47 & 1.50 & 1.56 \\
\hline Minimum & 1.00 & 1.20 & 1.60 & 1.35 & 1.45 & 1.50 & 1.00 & 1.15 & 1.20 \\
\hline Maximum & 1.80 & 1.60 & 1.85 & 2.05 & 2.00 & 2.25 & 2.20 & 2.10 & 2.20 \\
\hline St. deviation & 0.16 & 0.17 & 0.13 & 0.23 & 0.20 & 0.25 & 0.28 & 0.23 & 0.27 \\
\hline
\end{tabular}

and finding the lowest root mean square error of an unconstrained non-linear multivariate function (Coleman and Li, 1996):

$M_{N}=\sqrt{\frac{\sum_{\lambda}\left[(\rho \mathrm{mes}-\rho \operatorname{sim})^{2}+(\tau \text { mes }-\tau \operatorname{sim})^{2}\right]}{n}}$

where $n$ is the number of wavelengths selected (three in this case), $\rho$ mes and $\tau$ mesare measured values of reflectance and transmittance, and $\rho \operatorname{sim}$ and $\tau$ simare simulated values of the three wavelengths $(\lambda)$.

Before using the PROSPECT model for simulation, it may be necessary to calibrate physical and optical constants such as the refractive index and absorption coefficients of leaf material with experimental data (Feret et al., 2008). Thus, forward simulations were first conducted using the retrieved $N$ values and input parameters corresponding to 38 broadleaf and 56 conifer needle samples randomly selected from the total sample. The suitability of the original PROSPECT model had been verified by calculating the RMSE between measured and simulated spectra of the selected samples. The RMSE was within the range of RMSEs documented in the literature (Feret et al., 2008). As a result, PROSPECT-4 was applied directly, without calibration, to simulate the spectra of the different types of sample leaves and needles.

To generate the LUTs, the PROSPECT model was run in the forward mode under two scenarios. In the first scenario, the model input parameters $\left(C_{\mathrm{m}}, C_{\mathrm{w}}\right.$ and $\left.N\right)$ were generated using a uniform distribution based on a maximum range available in the literature (Table 3) (Combal et al., 2003; Malenovsky et al., 2006; Féret and Asner, 2011). In the second scenario, the maximum and minimum values of the input parameters were set based on samples statistics as prior information. The values of $C_{\mathrm{m}}$ and $C_{\mathrm{w}}$ were set based on the maximum and minimum values of the samples collected in the field (Table 2). For structural parameter $N$, we used the retrieved range presented in Table 4 in the Results section. During all simulations, chlorophyll content was arbitrarily set to $40 \mu \mathrm{g} / \mathrm{cm}^{2}$. All possible combinations of the input variables were systematically used to generate LUT records.

There was high variation in the spectral properties between broadleaf and conifer needle samples. In order to observe the effect of sample heterogeneity on accuracy (i.e., $R^{2}$ and RMSE) we ran the model with and without stratifying the samples into broadleaves and conifer needles. Running the model in forward mode generated a LUT for conifer needle and broadleaf samples separately, as well as for the samples pooled when constrained approach was applied. The unconstrained method yielded 156,978 LUT records $\left(51 N \times 54 C_{\mathrm{m}} \times 57 C_{\mathrm{w}}\right)$. When the maximum and minimum limits of the input parameters were constrained by prior information, there was a large reduction in the total number of LUT records: to $7182\left(18 \mathrm{~N} \times 21 C_{\mathrm{m}} \times 19 C_{\mathrm{w}}\right)$ for broadleaf, $43,290\left(26 \mathrm{~N} \times 37 C_{\mathrm{m}} \times 45 C_{\mathrm{w}}\right)$ for conifer needles and $74,360\left(26 N \times 52 C_{\mathrm{m}} \times 55 C_{\mathrm{w}}\right)$ for the pooled samples. The computation time for generating the LUT varied according to the volume of the LUT.

\subsubsection{Model inversion and validation}

The PROSPECT input parameters $\left(N, C_{\mathrm{m}}\right.$ and $\left.C_{\mathrm{w}}\right)$ and the two leaf functional traits (LDMC and SLA) were simultaneously retrieved by searching the best matches to the measured spectra in the generated LUT. During inversion, LDMC was represented by $C_{\mathrm{m}} /\left(C_{\mathrm{m}}+C_{\mathrm{w}}\right)$ as shown on Eq. (6) and SLA as inverse of $C_{\mathrm{m}}$. This is to minimize effects of measurement errors of $C_{\mathrm{m}}$ and $C_{\mathrm{w}}$ on LDMC and SLA estimates when inversion with prior information was used. Otherwise the two leaf traits are totally dependent on $C_{\mathrm{m}}$ and $C_{\mathrm{w}}$ and can be computed from the estimated values of these model input parameters.

Two searching algorithms were used in the inversion process. For the LUT generated without prior information we used an unconstrained approach which depended solely on comparing the similarity between simulated and measured spectra. This was done by computing the RMSE and finding its lowest value, using the merit function $\left(M_{N}\right)$ in Eq. (7). However, different sets of input variables and simulated spectra could result in to the same RMSE when compared with the measured data. Therefore, when (spectral) RMSE is the criterion to search the best match, multiple solutions may exist in the LUT. To overcome this limitation, the LUTs generated with prior information were inverted by using mean and variance of the measured input parameters as a constraint in addition to measuring the similarities between the observed and simulated spectra (Eq. (8)) (Combal et al., 2003; Malenovsky et al., 2006; Lauvernet et al., 2008; Jacquemoud et al., 2009). The estimations of all the variables were made using all available wavelengths in the NIR and SWIR (801-2350 nm). 


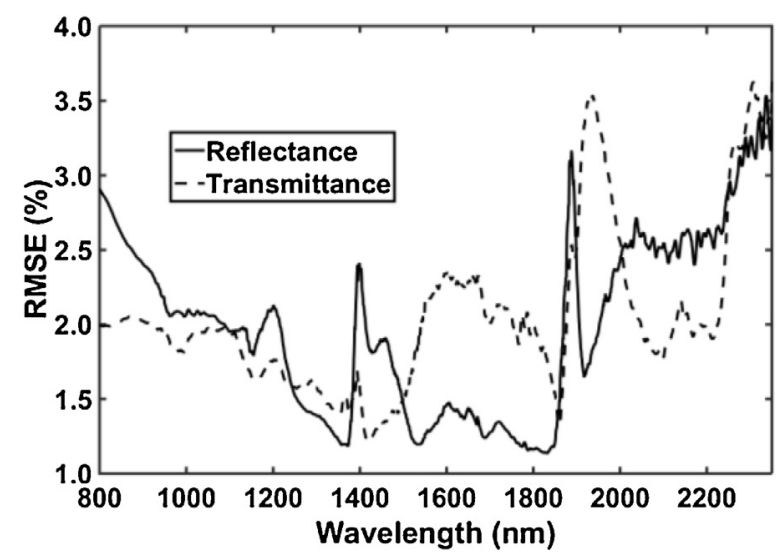

Fig. 4. Root Mean Square Errors (RMSE) computed between the measured and PROSPECT simulated reflectance and transmittance for the 137 leaf and needle samples.

$(8) M_{N}=\sum_{\lambda} \frac{(\rho \text { mes }-\rho \operatorname{sim})^{2}}{\sigma_{\rho \mathrm{mes}}^{2}}+\sum_{\lambda} \frac{(\tau \mathrm{mes}-\tau \operatorname{sim})^{2}}{\sigma_{\tau \mathrm{mes}}^{2}}+$ $\sum_{j} \frac{\left(V_{j}-V_{j}^{\text {prior }}\right)^{2}}{\sigma_{V_{j} \text { mes }}^{2}}$ where $V_{j}$ is the estimated value of the simultaneously retrieved variables such as $C_{\mathrm{m}}, C_{\mathrm{w}}, \mathrm{LDMC}, \mathrm{SLA}$ and $N, V_{\mathrm{j}}$ prior is the measured prior value of the variable $j$ (i.e., means of $C_{\mathrm{m}}, C_{\mathrm{w}}$, LDMC and SLA in Table 2 and mean of $N$ in Table 4$), \sigma_{\rho \text { mes }}^{2}$ and $\sigma_{\tau \text { mes }}^{2}$ are variances of the measured reflectance and transmittance respectively and $\sigma_{V_{j} \text { mes }}^{2}$ is the variance of the measured input variable $j$. The estimated parameters were then plotted against the measured leaf trait concentrations and evaluated by means of root mean square error (RMSE); normalized RMSE (nRMSE) was calculated as RMSE divided by the mean of the given variable and coefficient of determination $\left(R^{2}\right)$.

\section{Results}

\subsection{Determination of the structural parameter $N$ and model suitability}

The retrieved values of $N$ range from 1 to 2.25. The maximum $N$ value was recorded for the $\mathrm{C}++$ age class of fir tree, while the minimum values were observed in Norway spruce $C$ age class needles and European beech leaves. The average $N$ values were 1.74 for Fir and 1.5 for Norway spruce. Among the broadleaf species, a higher mean value of $N$ (1.7) was observed in Mountain ash (Table 4).

In order to evaluate the suitability of the leaf model, we calculated $R^{2}$ and the RMSE between measured spectra and the corresponding simulated spectra. The hemispherical reflectance and transmittance measured in laboratory and simulated using the PROSPECT-4 leaf model are illustrated in Fig. 3. Both the reflectance and transmittance signatures showed good matching throughout the NIR-SWIR region ( $R^{2}$ value of 0.99 and 0.97 for reflectance and transmittance respectively). Greater disagreement (RMSE close to $3.5 \%$ ) was observed in the wavelength range from 1900 to $2350 \mathrm{~nm}$ (Fig. 4) for both reflectance and transmittance. The mean RMSE for both reflectance and transmittance was near $2 \%$. Mean spectral values also showed the resemblance of the simulated spectra to the measured spectral information. Nevertheless, more deviations between the measured and simulated mean values were observed for reflectance than for transmittance.

\subsection{Retrieval of traits by inversion and evaluation}

The LUTs were used to search for the matches of all the input variables and the two traits (i.e., LDMC and SLA) using Eqs. (7) and (8). The variations between the measured values with values retrieved with or without constraining information are presented in Table 5. The retrieval ability of the unconstrained search algorithm ranges from an nRMSE value of 0.8291 (for SLA of broadleaf samples) to 0.2046 (for the LDMC of pooled samples). In most cases, the lowest nRMSE was observed for LDMC.

The retrieval of SLA showed poor performance for most of the unconstrained inversion cases, ranging for nRMSE between 0.6903-0.8291. In all cases, the application of prior information enormously improved the accuracy of the retrieved values, as expected. For instance, in broadleaf samples, when prior information was used the nRMSE between the measured and estimated values dropped from 0.4683 to 0.2278 for $C_{\mathrm{m}}$, from 0.2909 to 0.2065 for $C_{\mathrm{w}}$ and from 0.2186 to 0.0925 for LDMC. Despite over estimation of lower and underestimation of higher values in some cases, the retrieved values with prior information were also showed a better relationship with the measured values in the scatter plots (Fig. 5). The nRMSE values for many of the retrieved variables with prior information are lower when the variables were retrieved for broadleaf and conifer samples separately than when retrieving the variables for the pooled samples. The lowest nRMSE was observed in all samples for LDMC. High $R^{2}$ values for the PROSPECT input parameters and the two leaf traits were detected in the pooled samples. In most cases, the correlation coefficient between retrieved and measures SLA was higher than LDMC, but the forecast precision of LDMC was better than that of SLA.

\section{Discussion and conclusions}

This study quantifies and estimates two important leaf functional traits: SLA and LDMC. These traits, which are not widely addressed in the field of remote sensing, can be accurately derived from the input parameters of the PROSPECT radiative transfer model. The model's performance was evaluated for samples from mixed forest. The results indicate that the PROSPECT_4 leaf model accurately simulates spectral information of samples from mixed mountain forests and can be used to retrieve the biochemical content of leaves/needles directly and indirectly through inversion. In some cases, we found higher accuracies for the indirect estimated variable (LDMC) than for the direct input variables of the model, which further supports the reliability of the indirect retrieval approach.

The values of the structural parameter $N$ in fir tree needles of three seasons or older were high compared to the $N$ values of the younger needles. This can be attributed to the lower water content in the older leaves and confirms earlier findings by Jacquemoud et al. (1996), who stated that for the same species, $N$ estimated on dry leaves is higher than the $N$ estimated for fresh leaves, due to an increase of multiple scattering resulting from the loss of water. Our estimated values of the structural parameter $N$ fit well within the known range (1.0-2.5) for a wide variety of species (Jacquemoud and Baret, 1990). However, Malenovsky et al. (2006) found higher values (1.72-2.63) of $N$ for Norway spruce; this might be because of site-specific nature of the parameter or the bias in spruce needle samples spectra measurement (particularly transmittance) (Fig. 2) could have negatively affected the retrieved $N$ values. The mean value of 1.42 for beech trees agrees with the results of Demarez et al. (1999), who studied the seasonal variation of $N$ for selected broadleaf tree species.

PROSPECT inversion with a priori information for broadleaf samples yielded an RMSE $=0.0018 \mathrm{~g} / \mathrm{cm}^{2}$ for $C_{\mathrm{m}}$, which confirms the 
Table 5

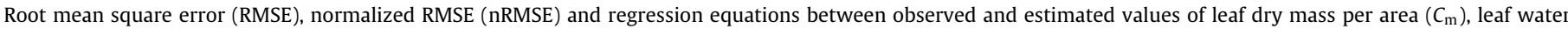
content per area $\left(C_{\mathrm{w}}\right)$, SLA and LDMC with or without prior information from inversion of the PROSPECT model for broadleaf leaf and conifer needle samples.

\begin{tabular}{|c|c|c|c|c|c|}
\hline Method & Category & Variable & RMSE & nRMSE & Regression equation \\
\hline \multirow{12}{*}{$\begin{array}{l}\text { Inversion without prior } \\
\text { information }\end{array}$} & \multirow[t]{4}{*}{ Broadleaf samples } & $C_{\mathrm{m}}$ & 0.0037 & 0.47 & $Y=0.52 x+0.00059$ \\
\hline & & $C_{\mathrm{w}}$ & 0.0024 & 0.26 & $Y=0.62 x+0.0019$ \\
\hline & & SLA & 112.25 & 0.83 & $Y=1.9 x-5.2$ \\
\hline & & LDMC & 100.7 & 0.22 & $Y=0.58 x+110$ \\
\hline & \multirow[t]{4}{*}{ Conifer samples } & $C_{\mathrm{m}}$ & 0.0086 & 0.43 & $Y=0.36 x+0.0054$ \\
\hline & & $C_{\mathrm{w}}$ & 0.0053 & 0.21 & $Y=0.73 x+0.0039$ \\
\hline & & SLA & 35.36 & 0.69 & $Y=0.68 x+48$ \\
\hline & & LDMC & 92.2 & 0.20 & $Y=0.86 x-18$ \\
\hline & \multirow[t]{4}{*}{ Pooled samples } & $C_{\mathrm{m}}$ & 0.0066 & 0.43 & $Y=0.97 x-0.00076$ \\
\hline & & $C_{\mathrm{w}}$ & 0.0044 & 0.24 & $Y=1.2 x+0.00075$ \\
\hline & & SLA & 63.88 & 0.76 & $Y=1.2 x+17$ \\
\hline & & LDMC & 119.9 & 0.26 & $Y=0.81 x+21$ \\
\hline \multirow{12}{*}{$\begin{array}{l}\text { Inversion with prior } \\
\text { information }\end{array}$} & \multirow[t]{4}{*}{ Broadleaf samples } & $C_{\mathrm{m}}$ & 0.0018 & 0.23 & $Y=0.41 x+0.0041$ \\
\hline & & $C_{\mathrm{w}}$ & 0.0019 & 0.21 & $Y=0.55 x+0.0043$ \\
\hline & & SLA & 26.7 & 0.20 & $Y=1.1 \mathrm{x}-2.8$ \\
\hline & & LDMC & 0.376 & 0.09 & $Y=0.74 \mathrm{x}+110$ \\
\hline & \multirow[t]{4}{*}{ Conifer samples } & $C_{\mathrm{m}}$ & 0.0032 & 0.16 & $Y=0.24 x+0.016$ \\
\hline & & $C_{\mathrm{w}}$ & 0.0033 & 0.13 & $Y=0.37 x+0.016$ \\
\hline & & SLA & 9.28 & 0.18 & $Y=0.22 x+38$ \\
\hline & & LDMC & 41.3 & 0.09 & $Y=0.33 x+150$ \\
\hline & \multirow[t]{4}{*}{ Pooled samples } & $C_{\mathrm{m}}$ & 0.0033 & 0.21 & $Y=0.63 x+0.0047$ \\
\hline & & $C_{\mathrm{w}}$ & 0.0036 & 0.19 & $Y=0.72 x+0.0041$ \\
\hline & & SLA & 21.73 & 0.26 & $Y=0.77 x+16$ \\
\hline & & LDMC & 40.8 & 0.09 & $Y=0.65 x+130$ \\
\hline
\end{tabular}

results of Romero et al. (2012), who estimated $C_{\mathrm{m}}$ of 11 selected species leaf samples by inversion of the model after removing unrealistic combinations between the input parameters from the LUT. The RMSE and range values for $C_{\mathrm{m}}$ for both broadleaf and conifer samples as well as for the pooled data were within the range reported by Asner et al. (2011), who estimated the $C_{\mathrm{m}}$ for 2871 samples collected from heterogeneous humid tropical rain forests. However, our estimation of $C_{\mathrm{m}}$ and $C_{\mathrm{w}}$ yielded a relatively less accurate result (RMSE $=0.0032$ and 0.0033 ) for conifer needles than the estimates obtained by Malenovsky et al. (2006), who studied Norway spruce needle samples by using the spectral range of $450-110 \mathrm{~nm}$. This is probably because the latter study was on mono species while in our samples there are a couple of conifer species. The high RMSE between the measured and simulated spectra in the SWIR range (Fig. 3) might be also the other cause.

Overall, the leaf trait LDMC was more accurately estimated than the other variables investigated in this study. One possible reason for such accurate estimate of LDMC could be the relatively smaller errors introduced during LDMC field measurement. It seems to be more challenging to measure $C_{\mathrm{m}}, C_{\mathrm{w}}$ and SLA reliably in the field, partly due to errors related to measuring the area of samples.

The results of the model inversion highlight the reliability and feasibility of using remote sensing data for estimation of leaf traits. The comparison of the spectral-based results of this study with field measurements indicates the potential of remote sensing data to estimate leaf traits over a range of vegetation types. This leaf-level result indicates that leaf traits, especially SLA and LDMC, are quantitatively represented by leaf spectra. Previous studies focused on the estimation of some or all of the direct input variables of PROSPECT model by using few bands of the visible and near infrared regions. Here we have shown that model inversion from a wide spectral range can provide indirect and direct estimates of multiple leaf traits for mixed mountain forests. Most importantly, this leaf-level analysis offers a basis to test the possible gains and losses incurred in scaling up to the canopy and landscape scale.

In this study we have demonstrated the inversion results from the wavelength range from 801 to $2350 \mathrm{~nm}$. Inversion based on selected spectral bands (not shown here) does not improve the retrieval accuracy. This is because of the informative nature of the whole shortwave spectral region for estimating variables related to leaf dry matter and thickness. Similar results have been reported in the tropical rain forest when using the soil leaf canopy model (Asner et al., 2009).

The evaluation results of the inversion presented in Fig. 5 and Table 5 demonstrated the inherent capacity of using prior information in improving the accuracy of the estimated variables using RTM inversion. This is in agreement with several previous studies (e.g., Malenovsky et al., 2006; Dasgupta et al., 2009). Besides limiting the upper and lower boundaries of the model input parameters, we used a modified cost function in the LUT search, which takes into account the uncertainty of the prior information on the variables to be estimated. However, the minimum distance between the measured and modeled spectra could probably be compromised for the uncertainty analysis, which is why we found a much lower RMSE between measured and simulated spectra during the inversion without prior information than during the inversion with prior information (Fig. 6).

It was observed that the RMSE between measured and observed spectra was higher for longer wavelengths than for shorter wavelengths (Fig. 4). This could be associated with several factors. One possible reason could be error associated with the equipment used for the spectral measurement. Our preliminary reliability test for adjusting gap fraction (GF) effect showed error inclusion during GF correction for conifer samples. This agrees with Yanez-Rausell et al. (2014), who tried to address the effect of gaps between samples and other factors affecting spectral measurement of conifer needles by using the integrating sphere. The GF effect is generally higher in the shortwave region than in the visible and near infrared region. Although the error was systematic and occurred across all samples, it probably contributed to the higher RMSE between the measured and PROSPECT simulated spectra shown in Fig. 4. This emphasizes the need for future studies to develop more accurate spectral measurement techniques.

The determination of SLA, $C_{\mathrm{m}}$ and $C_{\mathrm{w}}$ requires accurate measurements of leaf area. But the calculation of areas of irregular shape, particularly conifer needles, is prone to error. Errors are introduced - particularly when calculating the area of conifer needle samples by the shadow effect while scanning samples, while classifying the scanned images to binary format, while rounding off pixels, by the correction factor used and by other procedures. Studies showed 

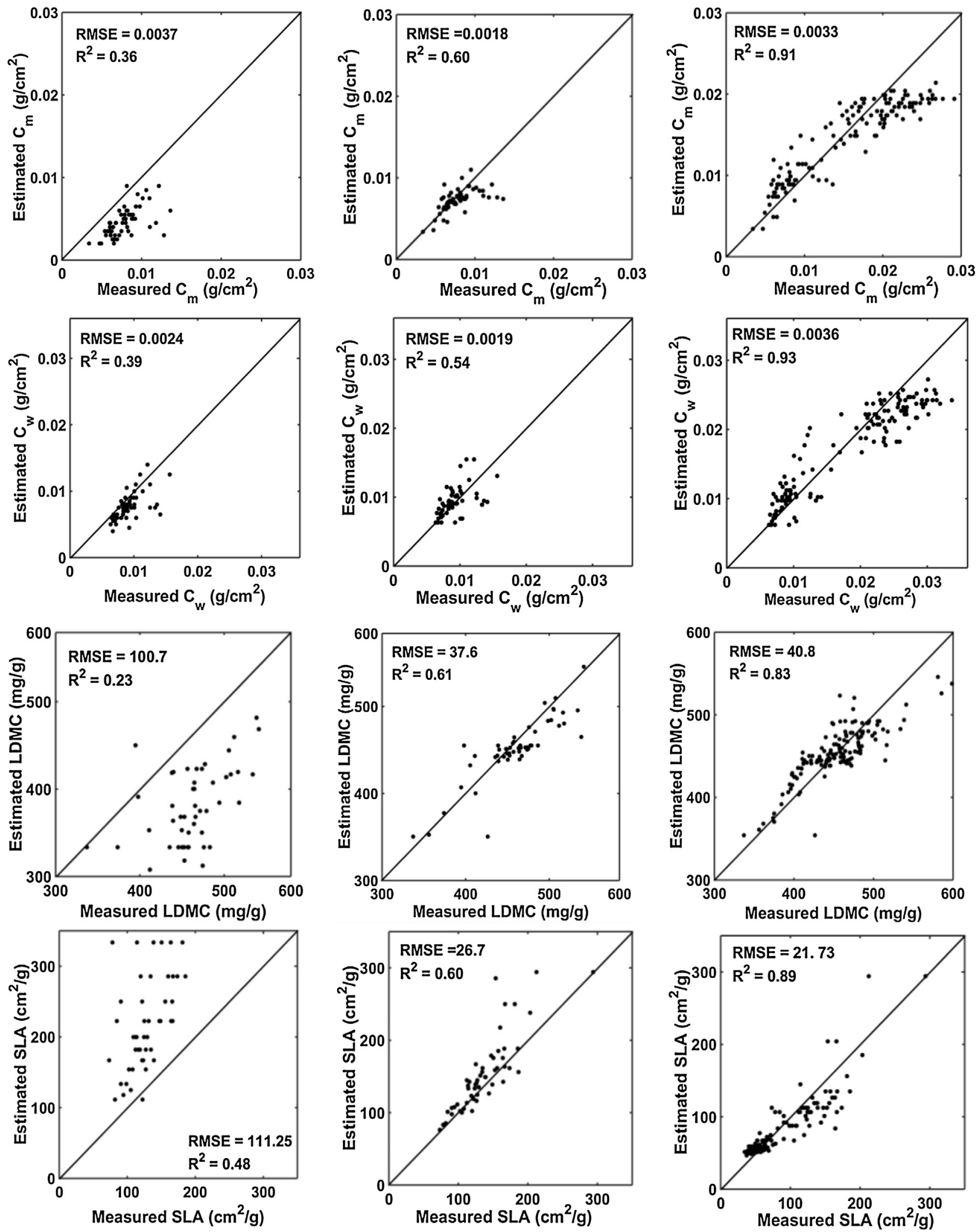

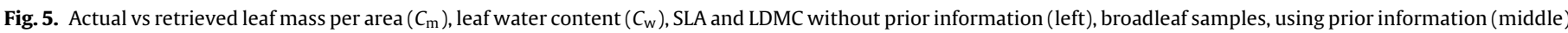
and pooled samples, using prior information (right). The solid line shows the 1:1 relation.

that the shape of the Norway spruce needles vary for different age classes and need different conversion factors (Homolova et al., 2013). But we simply used a universal conversion factor from literature which could be source of error. Although it is not possible to avoid all these errors, in future studies efforts should be made to develop simple and fast techniques for computing needle area and for optical property measurement of narrow leaf samples by using the integrating sphere. 


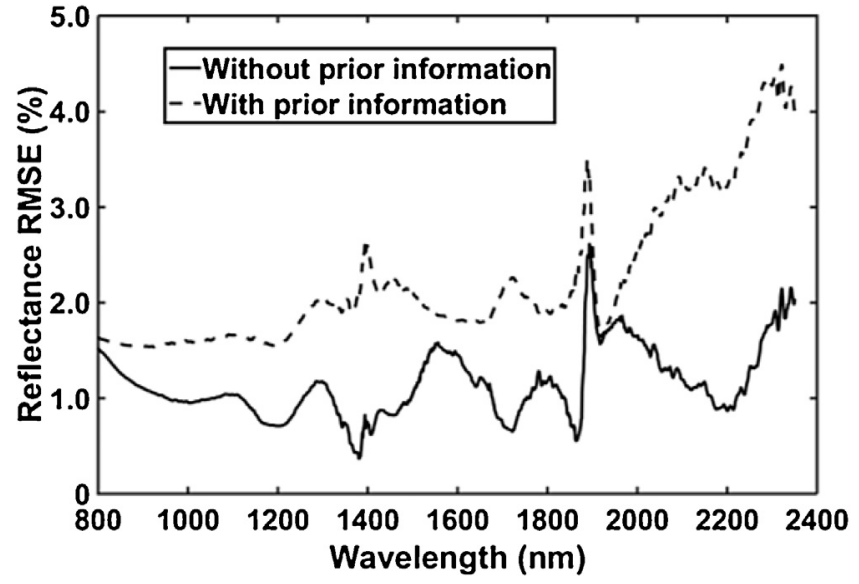

Fig. 6. Root Mean Square Errors (RMSE) computed between the measured and PROSPECT simulated reflectance for the 53 broadleaf samples with and without using prior information.

In general, our results have confirmed that two important leaf functional traits are measurable with spectral information. This in turn highlights the potential to extend the study to canopy and landscape scales by using advanced hyperspectral airborne and spaceborne sensors. However, it is worth mentioning that when the observational scale moves from leaf to canopy and landscape scales, the relationship between reflected radiation and leaf traits may change (Ustin et al., 2009). The spectral properties caused by leaf traits are then affected by soil, non-photosynthetic vegetation, stem characteristics, canopy structure, shadows, illumination and view angles (Roberts et al., 2004; Ollinger et al., 2008). Retrieval methods that have been designed at leaf scale are likely to suffer from these structural and external factors when used at canopy scale (Asner et al., 1998). Therefore, further study is needed to understand the impact of canopy structural and external factors (such as sun zenith and azimuth angles) other than the leaf functional traits on canopy reflectance in order to accurately estimate the two functional traits from remote-sensing data at canopy or landscape scale.

\section{Acknowledgments}

This study was funded by Nuffic-Netherlands fellowship program. We acknowledge the assistance of Dr. Nicole Pinnel in German Remote Sensing Data Center, German Aerospace Center Earth Observation Center (DLR) and Dr. Hooman Latifi in Institute of Geography and Geology, University of Wuerzburg in selecting the test site, and organizing and facilitating the field campaign. Thanks also go to the Bavarian Forest National Parks for approving access to the study area, providing the crossbow with its accessories, and other field and camping facilities. The authors also wish to thank Zhihui Wang and Tiejun Wang in the faculty of Geo-Information Science and Earth Observation, University of Twente, who assisted with the fieldwork design and data collection. Dr. Joy Burrough was the language editor of a near-final draft of the paper.

\section{References}

Albert, C.H., Thuiller, W., Yoccoz, N.G., Soudant, A., Boucher, F., et al., 2010. Intraspecific functional variability: extent, structure and sources of variation. J. Ecol. 98 (3), 604-613.

Asner, G.P., Braswell, B.H., Schimel, D.S., Wessman, C.A., 1998. Ecological research needs from multiangle remote sensing data. Remote Sens. Environ. 63 (2), $155-165$

Asner, G.P., Martin, R.E., 2008. Spectral and chemical analysis of tropical forests: scaling from leaf to canopy levels. Remote Sens. Environ. 112 (10), 3958-3970.
Asner, G.P., Martin, R.E., 2009. Airborne spectranomics: mapping canopy chemical and taxonomic diversity in tropical forests. Front. Ecol. Environ. 7 (5), 269-276 Asner, G.P., Martin, R.E., 2012. Contrasting leaf chemical traits in tropical lianas and trees: implications for future forest composition. Ecol. Lett. 15 (9), 1001-1007.

Asner, G.P., Martin, R.E., Ford, A.J., Metcalfe, D.J., Liddell, M.J., 2009. Leaf chemical and spectral diversity in Australian tropical forests. Ecol. Appl. 19 (1), 236-253.

Asner, G.P., Martin, R.E., Tupayachi, R., Emerson, R., Martinez, P., et al., 2011. Taxonomy and remote sensing of leaf mass per area (LMA) in humid tropical forests. Ecol. Appl. 21 (1), 85-98.

Broge, N.H., Mortensen, J.V., 2002. Deriving green crop area index and canopy chlorophyll density of winter wheat from spectral reflectance data. Remote Sens. Environ. 81 (1), 45-57.

Cadotte, M.W., Carscadden, K., Mirotchnick, N., 2011. Beyond species: functional diversity and the maintenance of ecological processes and services. J. Appl. Ecol. 48 (5), 1079-1087.

Cadotte, M.W., Cavender-Bares, J., Tilman, D., Oakley, T.H., 2009. Using phylogenetic, functional and trait diversity to understand patterns of plant community productivity. PLoS One 4 (5), e5695.

Carlson, K.M., Asner, G.P., Hughes, R.F., Ostertag, R., Martin, R.E., 2007. Hyperspectral remote sensing of canopy biodiversity in Hawaiian lowland rainforests. Ecosystems 10 (4), 536-549.

Coleman, T.F., Li, Y.Y., 1996. An interior trust region approach for nonlinear minimization subject to bounds. Siam J. Optim. 6 (2), 418-445.

Combal, B., Baret, F., Weiss, M., Trubuil, A., Mace, D., et al., 2003. Retrieval of canopy biophysical variables from bidirectional reflectance-Using prior information to solve the ill-posed inverse problem. Remote Sens. Environ. 84 (1), 1-15.

Cornelissen, J.H.C., Lavorel, S., Garnier, E., Diaz, S., Buchmann, N., et al., 2003. A handbook of protocols for standardised and easy measurement of plant functional traits worldwide. Aust. J. Bot. 51 (4), 335-380.

Darvishzadeh, R., Skidmore, A., Schlerf, M., Atzberger, C., 2008a. Inversion of a radiative transfer model for estimating vegetation LAI and chlorophyll in a heterogeneous grassland. Remote Sens. Environ. 112 (5), 2592-2604.

Darvishzadeh, R., Skidmore, A., Schlerf, M., Atzberger, C., Corsi, F., et al., 2008b. LAI and chlorophyll estimation for a heterogeneous grassland using hyperspectral measurements. ISPRS J. Photogramm. Remote Sens. 63 (4), 409-426.

Dasgupta, S., Qu, J.J., Bhoi, S., 2009. Constrained radiative transfer inversions for vegetation moisture retrievals in grasslands. J. Appl. Remote Sens. 3.

Daughtry, C.S.T., Biehl, L.L., Ranson, K.J., 1989. A new technique to measure the spectral properties of conifer needles. Remote Sens, Environ. 27 (1), 81-91.

Dawson, T.P., Curran, P.J., Plummer, S.E., 1998. LIBERTY-modeling the effects of leaf biochemical concentration on reflectance spectra. Remote Sens. Environ. 65 (1), 50-60.

Demarez, V., Gastellu-Etchegorry, J.P., Mougin, E., Marty, G., Proisy, C., et al., 1999 Seasonal variation of leaf chlorophyll content of a temperate forest. Inversion of the PROSPECT model. Int. J. Remote Sens. 20 (5), 879-894.

Díaz, S., Cabido, M., 2001. Vive la diffírence: plant functional diversity matters to ecosystem processes. Trends Ecol. Evol. 16 (11), 646-655.

Féret, J.-B., Asner, G.P., 2014. Mapping tropical forest canopy diversity using high-fidelity imaging spectroscopy. Ecol. Appl.

Féret, J.B., Asner, G.P., 2011. Spectroscopic classification of tropical forest species using radiative transfer modeling. Remote Sens. Environ. 115 (9), 2415-2422.

Feret, J.B., Francois, C., Asner, G.P., Gitelson, A.A., Martin, R.E., et al., 2008. PROSPECT-4 and 5: advances in the leaf optical properties model separating photosynthetic pigments. Remote Sens. Environ. 112 (6), 3030-3043.

Feret, J.B., Francois, C., Gitelson, A., Asner, G.P., Barry, K.M., et al., 2011. Optimizing spectral indices and chemometric analysis of leaf chemical properties using radiative transfer modeling. Remote Sens. Environ. 115 (10), 2742-2750.

Gould, W., 2000. Remote sensing of vegetation, plant species richness, and regional biodiversity hotspots. Ecol. Appl. 10 (6), 1861-1870.

Gregory, A., 2008. Hyperspectral remote sensing of canopy chemistry, physiology, and biodiversity in tropical rainforests. In: Hyperspectral Remote Sensing of Tropical and Sub-Tropical Forests. CRC Press, pp. 261-296.

Heurich, M., Beudert, B., Rall, H., Krenova, Z., 2010. National Parks as model regions for interdisciplinary long-term ecological research. In: Müller, F., Baessler, C., Schubert, H., Klotz, S. (Eds.), Long-term Ecological Research. Between Theory and Application. Springer, Netherlands, pp. 327-344.

Heurich, M., Neufanger, M., 2005. Die Wälder des Nationalparks Bayerischer Wald. Ergebnisse der Waldinventur 2002/2003 im geschichtlichen und waldökologischen Kontext. Grafenau, $178 \mathrm{~S}$.

Hodgson, J.G., Montserrat-Marti, G., Charles, M., Jones, G., Wilson, P., et al., 2011. Is leaf dry matter content a better predictor of soil fertility than specific leaf area? Ann. Bot. 108 (7), 1337-1345.

Homolova, L., Lukes, P., Malenovsky, Z., Lhotakova, Z., Kaplan, V., et al., 2013. Measurement methods and variability assessment of the Norway spruce total leaf area: implications for remote sensing. Trees-Struct. Funct. 27 (1), 111-121.

Jacquemoud, S., Baret, F., 1990. Prospect-a model of leaf optical-properties spectra. Remote Sens. Environ. 34 (2), 75-91.

Jacquemoud, S., Ustin, S.L., Verdebout, J., Schmuck, G., Andreoli, G., et al., 1996. Estimating leaf biochemistry using the PROSPECT leaf optical properties model. Remote Sens. Environ. 56 (3), 194-202.

Jacquemoud, S., Verhoef, W., Baret, F., Bacour, C., Zarco-Tejada, PJ., et al., 2009. PROSPECT plus SAIL models: a review of use for vegetation characterization. Remote Sens. Environ. 113, S56-S66.

Kattge, J., Díaz, S., Lavorel, S., Prentice, I.C., Leadley, P., et al., 2011. TRY-a global database of plant traits. Global Change Biol. 17 (9), 2905-2935. 
Kleyer, M., Bekker, R.M., Knevel, I.C., Bakker, J.P., Thompson, K., et al., 2008. The LEDA Traitbase: a database of life-history traits of the Northwest European flora. J. Ecol. 96 (6), 1266-1274.

Knox, N.M., Skidmore, A.K., Schlerf, M., de Boer, W.F., van Wieren, S.E., et al., 2010. Nitrogen prediction in grasses: effect of bandwidth and plant material state on absorption feature selection. Int. J. Remote Sens. 31 (3), 691-704.

Laurent, V.C.E., Verhoef, W., Clevers, J.G.P.W., Schaepman, M.E., 2011. Estimating forest variables from top-of-atmosphere radiance satellite measurements using coupled radiative transfer models. Remote Sens. Environ. 115 (4), 1043-1052.

Lauver, C.L., 1997. Mapping species diversity patterns in the Kansas shortgrass region by integrating remote sensing and vegetation analysis. J. Veg. Sci. 8 (3), 387-394.

Lauvernet, C., Baret, F., Hascoet, L., Buis, S., Le Dimet, F.X., 2008.

Multitemporal-patch ensemble inversion of coupled surface-atmosphere radiative transfer models for land surface characterization. Remote Sens. Environ. 112 (3), 851-861.

Lavorel, S., Grigulis, K., Lamarque, P., Colace, M., Garden, D., et al., 2011. Using plant functional traits to understand the landscape distribution of multiple ecosystem services. J. Ecol. 99 (1), 135-147.

le Maire, G., Francois, C., Soudani, K., Berveiller, D., Pontailler, J.Y., et al., 2008 Calibration and validation of hyperspectral indices for the estimation of broadleaved forest leaf chlorophyll content, leaf mass per area, leaf area index and leaf canopy biomass. Remote Sens. Environ. 112 (10), 3846-3864.

Lymburner, L., Beggs, P.J., Jacobson, C.R., 2000. Estimation of canopy-average surface-specific leaf area using Landsat TM data. Photogramm. Eng. Remote Sens. 66 (2), 183-191.

Ma, Z.G., Chen, X., Wang, Q., Li, P.H., Jiapaerl, G., 2012. Retrieval of leaf biochemical properties by inversed PROSPECT model and hyperspectral indices: an application to Populus euphratica polymorphic leaves. J. Arid Land 4 (1), 52-62.

Malenovsky, Z., Albrechtova, J., Lhotakova, Z., Zurita-Milla, R., Clevers, J.G.P.W., et al., 2006. Applicability of the PROSPECT model for Norway spruce needles. Int. J. Remote Sens. 27 (23-24), 5315-5340.

Malenovský, Z., Martin, E., Homolová, L., Gastellu-Etchegorry, J.-P., Zurita-Milla, R., et al., 2008. Influence of woody elements of a Norway spruce canopy on nadir reflectance simulated by the DART model at very high spatial resolution. Remote Sens. Environ. 112 (1), 1-18.

Mesarch, M.A., Walter-Shea, E.A., Asner, G.P., Middleton, E.M., Chan, S.S., 1999. A revised measurement methodology for conifer needles spectral optical properties: evaluating the influence of gaps between elements. Remote Sens. Environ. 68 (2), 177-192.

Morsdorf, F., Nichol, C., Malthus, T., Woodhouse, I.H., 2009. Assessing forest structural and physiological information content of multi-spectral LiDAR waveforms by radiative transfer modelling. Remote Sens. Environ. 113 (10), 2152-2163.

Ollinger, S.V., Richardson, A.D., Martin, M.E., Hollinger, D.Y., Frolking, S.E., et al, 2008. Canopy nitrogen, carbon assimilation, and albedo in temperate and boreal forests: functional relations and potential climate feedbacks. Proc. Natl. Acad. Sci. U. S. A. 105 (49), 19336-19341.

Papeş, M., Tupayachi, R., Martínez, P., Peterson, A.T., Powell, G.V.N., 2010. Using hyperspectral satellite imagery for regional inventories: a test with tropical emergent trees in the Amazon Basin. J. Veg. Sci. 21 (2), 342-354.

Petchey, O.L., Gaston, K.J., 2006. Functional diversity: back to basics and looking forward. Ecol. Lett. 9 (6), 741-758.

Pierce, L.L., Running, S.W., Walker, J., 1994. Regional-scale relationships of leaf-area index to specific leaf-area and leaf nitrogen-content. Ecol. Appl. 4 (2), 313-321.

Ramoelo, A., Skidmore, A.K., Cho, M.A., Schlerf, M., Mathieu, R., et al., 2012. Regional estimation of savanna grass nitrogen using the red-edge band of the spaceborne RapidEye sensor. Int. J. Appl. Earth Obs. Geoinf. 19, 151-162.
Ramoelo, A., Skidmore, A.K., Schlerf, M., Mathieu, R., Heitkonig, I.M.A., 2011. Water-removed spectra increase the retrieval accuracy when estimating savanna grass nitrogen and phosphorus concentrations. ISPRS J. Photogramm. Remote Sens, 66 (4), 408-417.

Rivera, J.P., Verrelst, J., Leonenko, G., Moreno, J., 2013. Multiple cost functions and regularization options for improved retrieval of leaf chlorophyll content and lai through inversion of the PROSAIL model. Remote Sens. 5 (7), 3280-3304.

Roberts, D.A., Ustin, S.L., Ogunjemiyo, S., Greenberg, J., Dobrowski, S.Z., et al., 2004 Spectral and structural measures of northwest forest vegetation at leaf to landscape scales. Ecosystems 7 (5), 545-562.

Romero, A., Aguado, I., Yebra, M., 2012. Estimation of dry matter content in leaves using normalized indexes and PROSPECT model inversion. Int. J. Remote Sens. 33 (2), 396-414.

Ruiliang, P., 2011. Detecting and mapping invasive plant species by using hyperspectral data. In: Hyperspectral Remote Sensing of Vegetation. CRC Press, pp. 447-466.

Saatchi, S., Buermann, W., Ter Steege, H., Mori, S., Smith, T.B., 2008. Modeling distribution of Amazonian tree species and diversity using remote sensing measurements. Remote Sens. Environ. 112 (5), 2000-2017.

Skidmore, A.K., Ferwerda, J.G., Mutanga, O., Van Wieren, S.E., Peel, M., et al., 2010. Forage quality of savannas-simultaneously mapping foliar protein and polyphenols for trees and grass using hyperspectral imagery. Remote Sens. Environ. 114 (1), 64-72

Smith, T.M., Shugart, H.H., Woodward, F.I., 1997. Plant Functional Types: Their Relevance to Ecosystem Properties and Global Change. Cambridge University Press, Cambridge, New York.

Tilman, D., 2001. Functional Diversity. Encyclopedia of Biodiversity. In: Simon, A.L. (Ed.). Elsevier, New York, pp. 109-120, Editor-in-Chief

Tilman, D., Knops, J., Wedin, D., Reich, P., Ritchie, M., et al., 1997. The influence of functional diversity and composition on ecosystem processes. Science 277 (5330), 1300-1302

Ustin, S.L., Gitelson, A.A., Jacquemoud, S., Schaepman, M., Asner, G.P., et al., 2009. Retrieval of foliar information about plant pigment systems from high resolution spectroscopy. Remote Sens. Environ. 113, S67-S77.

Vile, D., Garnier, É., Shipley, B., Laurent, G., Navas, M.-L., et al., 2005. Specific leaf area and dry matter content estimate thickness in laminar leaves. Ann. Bot. 96 (6), 1129-1136

Violle, C., Navas, M.L., Vile, D., Kazakou, E., Fortunel, C., et al., 2007. Let the concept of trait be functional! Oikos 116 (5), 882-892.

Vohland, M., Jarmer, T., 2008. Estimating structural and biochemical parameters for grassland from spectroradiometer data by radiative transfer modelling (PROSPECT plus SAIL). Int. J. Remote Sens. 29 (1), 191-209.

Waring, R.H., 1983. Estimating forest growth and efficiency in relation to canopy leaf-area. Adv. Ecol. Res. 13, 327-354.

Wilson, P.J., Thompson, K.E.N., Hodgson, J.G., 1999. Specific leaf area and leaf dry matter content as alternative predictors of plant strategies. New Phytol. 143 (1), 155-162.

Wright, I.J., Reich, P.B., Westoby, M., Ackerly, D.D., Baruch, Z., et al., 2004. The worldwide leaf economics spectrum. Nature 428 (6985), 821-827.

Yanez-Rausell, L., Malenovsky, Z., Clevers, J.G.P.W., Schaepman, M.E., 2014. Minimizing measurement uncertainties of coniferous needle-leaf optical properties. Part II: Experimental setup and error analysis. IEEE J. Sel. Top. Appl. Earth Obs. Remote Sens. 7 (2), 406-420.

Zhang, J.T., Fan, L., Li, M., 2012. Functional diversity in plant communities: theory and analysis methods. Afr. J. Biotechnol. 11 (5), 1014-1022.

Zhang, Y.Q., Chen, J.M., Miller, J.R., Noland, T.L., 2008. Retrieving chlorophyll content in conifer needles from hyperspectral measurements. Can. J. Remote Sens. 34 (3), 296-310 